\title{
PARCERIAS ESTRATÉGICAS PARA A INTERNACIONALIZAÇÃO: DESAFIOS A PARTIR DA EXPERIÊNCIA COM A UNIVERSIDADE DE LYON
}

\author{
Fernando Menezes de Almeida ${ }^{1}$ \\ Nina Ranieri ${ }^{2}$
}

\section{Apresentação}

Por ocasião da comemoração dos 50 anos da implantação do Programa de Pós-Graduação em Direito (PPGD) da Faculdade de Direito (FD) da Universidade de São Paulo (USP) - e acompanhando a criação, na mesma ocasião, do atual modelo de sistema de pós-graduação no Brasil -, ocorreu-nos registrar a experiência que temos tido, como docentes do programa, no âmbito de uma parceria estratégica de especial sucesso, visando à cooperação acadêmica internacional. Trata-se da parceria entre a Universidade de São Paulo e a Universidade de Lyon (UL), ${ }^{3}$ com especial ênfase nas relações entre suas faculdades de Direito.

O registro, neste texto, de duas das principais iniciativas decorrentes dessa parceria tem por objetivo, de um lado, levar ao conhecimento público sua modelagem, os passos de sua edificação, os instrumentos de sua operação, os seus resultados e os desafios para a institucionalização de iniciativas análogas, preservando, assim, a memória da experiência e servindo potencialmente de modelo a ser aprimorado e difundido; e, de outro, enfatizar a importância da internacionalização para a atividade acadêmica, a qual, se sempre existiu, ganha novo patamar de relevância em tempos de globalização.

\section{Breve histórico da parceria}

Em um texto com o sentido de registro histórico, ${ }^{4}$ cabe mencionar algumas pessoas que estiveram presentes na concepção inicial da parceria, sem

\footnotetext{
Professor Titular do Departamento de Direito do Estado.

Professora Associada do Departamento de Direito do Estado.

3 Universidade de Lyon é a designação de uma união de estabelecimentos de ensino superior situados em Lyon e em localidades próximas. Dos integrantes da Universidade de Lyon, destacam-se por sua proximidade na parceria com a USP, na área do Direito, a Universidade Jean Moulin Lyon 3, a Universidade Lumière Lyon 2 e a Universidade Jean Monnet de Saint-Étienne. Já a Universidade Claude Bernard Lyon 1, igualmente estabelecimento de excelência a integrar a Universidade de Lyon, não possui faculdade de Direito.

4 Lembrando algumas obras de Boris Fausto (tais como O crime da Galeria de Cristal - e os dois crimes da mala, São Paulo 1908/1928, São Paulo: Companhia das Letras, 2019; O crime do Restaurante Chinês, São Paulo: Companhia das Letras, 2009) e nos aproximando de uma perspectiva de micro-história, ou seja, com delimitação temática específica por parte dos autores.
} 
deixar de reconhecer a relevância de tantos outros indivíduos fundamentais para seu desenvolvimento e manutenção.

Em 2011, por iniciativa de um grande parceiro da USP e nosso amigo pessoal, Thierry Valentin - docente de Antropologia da Universidade Lyon 2, mas, naquela ocasião, já há algum tempo residente em São Paulo como diretor do Campus France -, organizou-se uma missão de cooperação da Universidade Lyon 3, liderada por seu então reitor, Hugues Fulchiron, professor de Direito, acompanhado, entre outros, pelo então pró-reitor de pesquisa e pós-graduação ${ }^{5}$ - e futuro reitor - Jacques Comby, professor de Geografia.

Naquele primeiro encontro, em que eu, Fernando, estive presente ${ }^{6}-$ e faço essa menção em primeira pessoa para reforçar o sentido do testemunho -, o professor Fulchiron declarou a decisão da Universidade Lyon 3 de tornar a USP sua parceira estratégica. Essa declaração - muitas vezes presente apenas formalmente na retórica das cooperações internacionais -, neste caso, foi realizada plenamente. Graças, em especial, ao empenho do professor Fulchiron, ${ }^{7}$ a parceria prosseguiu com igual ênfase por parte do professor Comby.

A partir desse primeiro encontro, as ações da parceria UL-USP seguiram num crescente até os dias de hoje. Isso se deu notadamente com as faculdades de Direito, mas também envolveu as reitorias e outras unidades acadêmicas de ambas as instituições.

Foram alguns seminários de pesquisa (organizados em âmbito geral das universidades); chamadas de auxílio à pesquisa com apoio da Fundação de Amparo à Pesquisa do Estado de São Paulo (Fapesp); diversos congressos científicos; ${ }^{8}$ teses desenvolvidas em programa de duplo-diploma; ${ }^{9}$ a outorga de doutorado honoris causa ao professor Celso Lafer, em 2012, pela Universidade Lyon 3; e, especialmente, dois programas que passamos a descrever em detalhes a seguir, por sua proximidade com o

\footnotetext{
A referência aos cargos está aqui adaptada à terminologia praticada na USP.

Como membro da Comissão de Cooperação Internacional e Nacional da FDUSP.

7 Um detalhe significativo nesse sentido foi a resposta dada por ele quando, na despedida do encontro (sob a forma de um almoço no pátio do restaurante Capim Santo, da Al. Min. Rocha Azevedo), eu, Fernando, perguntei quem da equipe dele seria a pessoa com quem eu deveria seguir mantendo as tratativas: afirmou categoricamente que seria ele mesmo o contato e já definiu que, na próxima vez que eu fosse à Europa - o que ocorreria dali a poucos meses, para um compromisso em Portugal -, visitasse Lyon e retomasse os planos, com ideias mais amadurecidas. De fato, foram esses os passos seguintes. Na ocasião, o professor Fulchiron apresentou-me Caroline Chamard-Heim, integrante de sua equipe, professora na mesma área de minha concentração (Direito Administrativo) e futura pró-reitora de planejamento na gestão do já mencionado professor Comby. Como será mencionado a seguir, Caroline, além de fraternal amiga, também se tornou peça-chave nessa parceria acadêmica.

8 O professor Fulchiron organizou, em parceria com a USP, ao menos dois eventos anuais nos últimos cinco anos: sobre Direito Internacional Privado e um projeto especial sobre o tema memória.

9 Duas já se concretizaram: a de Emilie Barbin, que eu, Fernando, coorientei com Caroline Chamard-Heim; e a de Jean Nicolau, coorientada por Gustavo Mônaco e Hugues Fulchiron.
} 
PPGD da nossa faculdade: o programa PITES (Parceria Internacional Triangular para o Ensino Superior) e os Seminários Doutorais.

\section{O programa PITES (Parceria Internacional Triangular para o Ensino Superior)}

Em 2014, a USP, a Universidade Jean Moulin Lyon 3 (Lyon 3), a Universidade Lumière Lyon 2 e a Universidade Jean Monnet de Saint-Étienne celebraram um acordo internacional para a realização de um programa de cooperação internacional com algumas características bastante especiais. ${ }^{10}$

São objetivos desse programa - que, essencialmente, é um programa de dupla diplomação no nível de graduação - oferecer formação acadêmica de excelência; garantir o máximo de acesso aos alunos de graduação a custos relativamente pequenos para as universidades e inexistentes para os alunos; e propiciar uma formação cultural e linguística franco-brasileira.

O PITES, desde a sua criação em $2014,{ }^{11}$ foi implementado nas faculdades de Direito das universidades envolvidas, mas seu modelo é perfeitamente compatível com outras áreas do conhecimento. Na prática, o programa se fez com a integração de um bloco de dez disciplinas das universidades lyonnaises à grade curricular da USP. Com

10 Novamente no plano da micro-história, a ideia do programa surgiu em uma reunião na então Comissão de Cooperação Internacional, na Reitoria, em 2012, quando um grupo de docentes de diversas unidades recebeu a visita de uma delegação de Lyon, desta vez presentes representantes (cito em especial o diretor de relações internacionais Jacques Skubich) da já referida "união" de universidades designada Universidade de Lyon (UL), acompanhando o senador André Ferrand (representante dos franceses établis hors de France), originário de Lyon. O senador Ferrand propôs uma parceria "triangular" entre universidades brasileiras (no caso, a USP), liceus franceses no Brasil (no caso, o Liceu Pasteur, em São Paulo) e universidades francesas (no caso, as integrantes da UL), para permitir que os alunos egressos do Liceu pudessem entrar em um programa especial da USP, com formação bi-diplomante franco-brasileira. Na ocasião, foi esclarecida à delegação francesa a impossibilidade legal e regimental da USP de reservar vagas para os egressos do Liceu. Mas a ideia essencial do programa - já intitulado pelo senador Ferrand como PITES - foi mantida, como será narrado a seguir. Até mesmo o nome foi mantido, improvisando-se uma adaptação do significado de "triangular" por se tratar, então, de uma parceria envolvendo estabelecimentos de Lyon, SaintEtienne e São Paulo. A modelagem do programa foi intensamente trabalhada nos anos seguintes, envolvendo um extraordinário esforço de colegas lyonnais, especialmente de Caroline ChamardHeim (entre outros pontos, elaborando o complexo texto do convênio e a grade de equivalências entre disciplinas da USP e de Lyon) e dos também caros amigos que, com Caroline e comigo, Fernando, são coordenadores do PITES em suas universidades: a professora Sylvie Bernigaud (Lyon 2) e o professor Aurélien Antoine (Saint-Etienne). No mesmo sentido, não se pode deixar de registrar, internamente à USP, a colaboração fundamental para o sucesso do PITES das professoras Sheila Neder e Camila Duran (também coordenadoras do programa na USP) e de Vima Matos, incansável secretária do PITES, sucessora de Eloíde Carneiro, que atuou intensamente para a implantação do programa.

11 Sendo seu primeiro docente Hugues Fulchiron, que, aliás, para garantir o cumprimento do cronograma inicialmente previsto, decidiu ministrar as aulas mesmo alguns meses antes de o trâmite burocrático do convênio sobre o programa estar assinado - consolidando, de fato, o que já estava apalavrado. 
isso, a USP abre-se para aceitar oficialmente que disciplinas de universidades parceiras sejam ao mesmo tempo consideradas disciplinas da USP.

Tais disciplinas são ministradas por docentes de Lyon 3, que vêm à USP como professores convidados para dar aulas em francês e sobre Direito francês. As disciplinas do programa são contadas simultaneamente como créditos da USP e de Lyon 3. Não se trata, pois, de um reconhecimento de "estudos cursados em outra instituição", mas, sim, de uma verdadeira integração de currículos, gerando um programa (parcialmente) comum.

Assim, os alunos da USP que cursarem a carga regular de disciplinas obrigatórias e de disciplinas optativas da USP - incluídas, na quota de disciplinas optativas, aquelas que integram o percurso do programa PITES - terão automaticamente ao final um diploma de bacharelado da USP e um diploma francês de licence - mais a certificação de carga horária correspondente a um ano de master francês.

As aulas de cada disciplina concentram-se em duas ou três semanas (30 ou 36 horas), de modo compatível com o currículo geral da FD.

Em termos logísticos, os professores é que se deslocam de um país a outro. Com isso, um número maior de discentes brasileiros pode ser atingido. Por outro lado, para aqueles alunos que desejarem, a possibilidade de cursar parte das disciplinas no exterior é fortemente estimulada.

$\mathrm{O}$ ingresso nesse programa é facultado a partir do $5^{\circ}$ semestre. São noventa vagas, das quais $20 \%$ são reservadas para alunos que tenham ingressado na FDUSP por cotas PPI. Noventa vagas anuais implicam que aproximadamente $20 \%$ do corpo discente da FDUSP possam terminar seu curso também com um diploma francês - além de, certamente, ganharem fluência na língua e inserção na cultura francesas.

O próximo passo, já em vias de implantação, é a continuidade do programa em nível de master francês e mestrado brasileiro. Para o master francês, já existe convênio assinado entre as universidades parceiras. ${ }^{12}$ Quanto ao mestrado brasileiro, no momento as tratativas estão em curso.

De qualquer modo, para o PPGD da USP, no limiar dos seus 50 anos, é uma boa e inovadora perspectiva que se delineia.

\section{Os Seminários Doutorais}

Outra iniciativa que tem se mostrado de grande sucesso no contexto da parceria Lyon 3-USP, e desde o início ligada ao PPGD, são os Seminários Doutorais. Sua

12 O PITES master, que deveria ter sido iniciado em 2020, foi adiado para 2021 em razão da pandemia de Covid-19. 
oferta, desde 2014, ${ }^{13}$ resulta de especial esforço de organização por parte da professora Caroline Chamard-Heim (Lyon 3).

Os Seminários Doutorais, fórmula francesa para a oferta de atividades de pós-graduação aos estudantes brasileiros, desenvolvem-se por meio de aulas teóricas (cours magistraux), reuniões com grupos de pesquisa formados por pós-graduandos locais e visitas a instituições públicas e privadas.

Todas as atividades integram as disciplinas de pós-graduação "Temas fundamentais de Direito Público francês" I, II e III,${ }^{14}$ credenciadas na FD com carga horária semestral regular. Oferecidas em sequência anual e com variedade temática, têm por objetivo analisar as especificidades das estruturas e as categorias do Direito Público francês.

A metodologia empregada combina aulas expositivas, discussões em classe e atividades fora da sala de aula, tanto na FD como na UL. Normalmente, a prática tem sido de oferta de aulas teóricas introdutórias na FD, complementadas por quatro dias de atividades na UL e um dia em Paris.

Nas atividades em Paris, o grupo estabelece contato com autoridades - que ministram conferências ou debatem mais diretamente com os participantes - e presencia o funcionamento real de instituições como o Conseil d'État, o Conseil Constitutionnel, a Cour de Cassation, a Cour des Comtes, a Assemblée Nationale e o Sénat. Nas seis edições do curso ocorridas até agora, sempre houve uma visita ao Conselho de Estado, seguida de visita a mais uma ou duas instituições variáveis a cada ano.

Em Lyon 3, as aulas são preparadas especialmente para os alunos brasileiros por colegas docentes franceses, voluntários. Os docentes da FD responsáveis pelas disciplinas também acompanham e participam das aulas.

Vale lembrar que, nos cursos de doutorado na França, não há aulas, mas exigência de pesquisa de alto nível, a ser desenvolvida em prazo máximo de 6 anos na área das ciências humanas. ${ }^{15}$ Os encontros promovidos entre pós-graduandos locais e brasileiros, portanto, são fundamentais para o fortalecimento das respectivas pesquisas, do multiculturalismo, da interdisciplinaridade e da formação de novos grupos e redes.

13 Novamente no plano da micro-história, um ensaio dessa experiência ocorreu em 2012, quando, por ocasião da entrega do título de doutor honoris causa ao professor Celso Lafer, na Universidade Lyon 3, além de alguns professores da USP, um grupo de uma dezena de mestrandos e doutorandos voluntariamente acompanhou o evento, passando por algumas visitas a instituições estatais e tendo contatos acadêmicos com docentes e pesquisadores de Lyon.

14 Pelas quais nós dois, autores deste texto, temos sido responsáveis, e já tendo contado em algumas edições com a companhia dos professores Sheila Neder e Vitor Schirato.

15 Cf. Campus France: https://www.bresil.campusfrance.org/descubra-ensino-superior-franca. 
Quanto às atividades extraclasse, sempre contando com a recepção de autoridades dispostas a esclarecer o seu funcionamento, há visitas programadas à Cour Administrative d'Appel, à Cour des Comptes, à Chambre Régionale des Comptes RhôneAlpes/Auvergne, ao Conseil Régional, à Cour d'Appel de Lyon e à Haute Autorité pour la Transparence de la Vie Publique.

As avaliações são feitas por meio de apresentação de trabalho de conclusão escrito, relativo a um dos temas abordados nas aulas em Lyon 3. O objetivo é proporcionar aos alunos a oportunidade de avançar além do que foi exposto e explorar problemas significantes para cada um deles. Nesse sentido, as disciplinas atestam, vigorosamente, o cumprimento de uma das missões essenciais da pós-graduação, que é incentivar a produção de doutrina contemporânea a partir de pesquisas científicas, o que se comprova diante da edição de obras com artigos produzidos originalmente como trabalhos finais das disciplinas. ${ }^{16}$

Nesse modelo, não há financiamento para a viagem, devendo cada aluno arcar com seus custos. De todo modo, não há nenhum custo adicional pelo curso propriamente dito, ou seja, a UL organiza nossa recepção e as aulas sem repassar custos à USP ou aos alunos.

Desde a edição inicial da pioneira disciplina "Temas fundamentais de Direito Público francês I", nota-se um aumento crescente de alunos brasileiros inscritos, assim como da participação de professores franceses. Os números de adesão ao programa são impressionantes. Em 2014, o grupo era formado por aproximadamente 25 pessoas. Na sexta edição, em 2019, a delegação da USP contou mais de 90 pessoas. ${ }^{17}$

\subsection{O conteúdo dos Seminários}

O conteúdo dos seminários na UL é definido em função do objetivo comum às disciplinas: o estudo aprofundado do Direito Público francês. A temática é sempre variada, buscando-se incluir tópicos atuais, significativos e úteis para os alunos. Ainda que vinculadas a realidades diferentes das por eles vivenciadas, as diferenças convergem para similaridades à vista da influência, no Brasil, do Direito Público francês.

\footnotetext{
16 CUNHA FILHO, Alexandre Carneiro et al. (coord.). Temas atuais de direito público: diálogos entre Brasil e França. Rio de Janeiro: Lumen Juris, 2016; CUNHA FILHO, Alexandre Carneiro et al. (coord.). Temas atuais de direito público: diálogos entre Brasil e França II. 2. ed. Rio de Janeiro: Lumen Juris, 2018; e ALMEIDA, Fernando Dias Menezes; ZAGO, Marina Fontão (coord.). Direito público francês: temas fundamentais. São Paulo: Quartier Latin, 2018.

17 Em 2020, devido à pandemia de Covid-19 e pela primeira vez desde a sua criação, o seminário não foi realizado.
} 
A variedade, ademais, permite abertura de contatos com docentes distintos, ampliando cada vez mais a rede de relações e parcerias para futuros desenvolvimentos de cooperação acadêmica.

Como registro, veja-se, como exemplo, as seguintes programações:

\section{5 - $2^{\text {ème }}$ Seminaire Doctoral}

1 - La revalorisation du Parlement en France (Philippe Blachèr)

2 - Présentation des finances publiques en France (M. Damien Catteau)

3 - Table ronde: Juriste et législateur: duo ou duel, dans le cadre du Collège de Droit

(Philippe Blachèr, David Cumin, Geneviève Gondouin e Cécile Untermaier)

4 -Droit des propriétés publiques (Caroline Chamard-Heim)

5 -Droit de l'Union européenne (Eric Carpano)

6 - Gestion des déchets et pollution des sols (Philippe Billet)

7 -Atelier: La liberté d'expression (M. Régis Fraisse, Conseiller d'Etat)

8 -Conférence: La déontologie des magistrats administratifs (Daniel Labetoulle e Christian Babusiaux).

\section{6 - $3^{\text {ème }}$ Seminaire Doctoral}

\section{Les frontières du Droit Public et du Droit Privé}

1 - Approche historique de la summa divisio (M. Le Doyen Louis-Augustin Barrière)

2 - Signification de la summa divisio (Pascale Deumier)

3 - La distinction Droit Public-Droit Privé et le Droit de l'Union européenne (M. Eric Carpano)

4 - Personnes et contrat (Aurélien Antoine)

5 -Question prioritaire de constitutionnalité: confirmation ou disparition de la frontière Droit Public-Droit Privé (Philippe Blachèr)

6 -Conférence: Propriété(s) publique et privée? (William Dross Caroline ChamardHeim)

7 - Conférence: L'office du juge administratif, pour Jean-Paul Martin

8 -Colloque: L'attractivité du Droit français des sûretés réelles, 10 ans après la réforme.

\section{$2017-4^{\text {ème }}$ Seminaire Doctoral}

\section{Actualités du Droit Public français}

1 -L'Etat d'urgence en France (Marie-Laure Basilien-Gainche)

2 - Introduction aux finances publiques françaises et enjeux liés à la discipline budgétaire et à la modernisation de la gestion publique (Damien Catteau)

3 -L'élection présidentielle française (Jean-François Kerléo)

4 - Le système fiscal français (Lukasz Stankiewicz)

5 -Approche du Droit de la commande publique (Michaël Karpenschif) 
6 - La démocratie administrative (Elise Untermaier-Kerléo)

7 - Le Brexit: et après (Eric Carpano).

\section{8 - $5^{\text {ème }}$ Seminaire Doctoral}

\section{Actualités du Droit Public français}

1 - La gestion des migrations en Europe (Marie-Laure Basilien-Gainche)

2 - La loi nouvelle et le contrat en cours: quelle(s) solution(s) pour le droit transitoire?

(Gatien Casu, maître de conférences en Droit Privé à l'Université Lyon 3)

3 -La protection des ressources naturelles par le droit: l'exemple de l'eau (Victoria Chiu)

4 - Le procès Klaus Barbie (Mathilde Philip-Gay)

5 - La culture du Droit en France et chez les anglo-saxons (Aurélien Antoine)

6 - La déontologie de la vie publique (Elise Untermaier-Kerléo)

7 -Colloque: Discrimination et fait religieux (journée de formation des acteurs de la justice) (Marie-Laure Basilien-Gainche).

\section{9 - $6^{\text {ème }}$ Seminaire Doctoral}

\section{Actualités du Droit Public français}

Paris - Visite et présentation générale du Conseil d'Etat avec M. l'auditeur au Conseil d'Etat Thibault Félix

1 - La nouvelle transparence fiscale internationale et les droits des contribuables: perspectives française et européenne (Lukasz Stankiewicz)

2 - Le Brexit (Aurélien Antoine)

3 - La restitution des œuvres d'art par la France (Christine Ferrari-Breeur)

4 -Les interactions de systèmes en Europe: l'exemple de l'affaire Mennesson (Laurent Eck)

5 -Audience au Tribunal administratif de Lyon (ch. 2): contentieux des étrangers, urbanisme, environnement, droit du travail etc.

6 - L'Union européenne: Etat des lieux d'un modèle d'intégration juridique en crise(s) (Gaëlle Marti)

7 - La réglementation des investissements étrangers en France et en Europe (François Barrière)

8 - La réforme du Droit de la commande publique (Efthymia Lekkou)

Como se pode notar, nesse período de 5 anos, os temas abordados demonstram a preocupação com a ampliação do horizonte jurídico dos alunos, apresentando-lhes desafios e inovações jurídicas que estimulam o pensamento crítico sobre o próprio sistema jurídico brasileiro. 
4.2. Alguns comentários de fundo sobre a temática dos Seminários

Embora o Direito francês integre a família dos sistemas jurídicos romano-germânicos e tenha influenciado o Direito brasileiro, em particular o Direito Administrativo, seu Direito Público afirmou-se em terreno jurídico particular, com regras específicas.

Deitando raízes no Antigo Regime, desenvolveu-se sob as influências do Iluminismo, da Revolução Francesa, da codificação napoleônica e do État de Droit. Após o final da Segunda Guerra Mundial, a afirmação dos direitos humanos, a construção da União Europeia, a reforma política do país e o enfrentamento de problemas econômicos e sociais por meio do Direito assinalaram um verdadeiro cisma com o antigo Direito Público francês, como assinala H. Fulchiron. ${ }^{18}$

Do ponto de vista dos direitos humanos, a grande alteração é a reconstrução do sistema jurídico francês sobre direitos e liberdades garantidos nos níveis nacional, europeu e internacional, e não mais exclusivamente sobre "a lei de expressão da vontade geral". De outra parte, o controle das leis e, por consequência, o novo papel dos juízes nessa tarefa (superando a tradicional atuação como bouche de la loi) constituem outros desdobramentos da prevalência dos direitos humanos.

No que tange à construção europeia, está claro que não é possível pensar o Direito francês sem considerar a produção normativa do Conselho da Europa e da União Europeia. A da União Europeia, em especial, supõe transferência de soberania nas áreas previstas em tratados específicos, assim como a prevalência, em determinadas áreas, da ordem jurídica comunitária sobre a ordem jurídica nacional. Outro aspecto importante é a inter-relação entre os diversos sistemas jurídicos europeus, consequência direta da base comum das regras comunitárias.

As atuais instituições políticas e administrativas francesas, sob a Constituição da V República, foram desenhadas - ou adaptadas - em face de problemas específicos do pós-guerra: instabilidade governamental (entre 1946 e 1958, sucederam-se vinte e um governos, com duração média de seis meses) e necessidade de modernização administrativa. Da reforma do sistema eleitoral e do fortalecimento do Executivo em relação ao Parlamento - num processo denominado racionalização do Parlamentarismo, mas que, na verdade, traduz um hiperpresidencialismo - à institucionalização de uma nova gestão do território francês, a partir dos anos 1980, fala-se mesmo de reinvenção do Estado francês. Isso tudo sem mencionar as diversas medidas políticas e jurídicas adotadas para sua integração à União Europeia, que interferem em sua soberania, e a recente

18 FULCHIRON, Huguest; ECK, Laurent. Introduction au Droit Français. Paris: LexisNexis, 2016. 
possibilidade de controle constitucional da lei, a posteriori ou em concreto (inexistente no Direito francês até 2009), por meio da questão prioritária de constitucionalidade.

Por fim, o Direito francês atual constitui-se em instrumento de políticas sociais e econômicas, a despeito da tendência de desregulação observada a partir da metade dos anos 1980. O que significa dizer que favorece - e não dirige - o desenvolvimento econômico.

Consideradas as suas origens e o seu desenvolvimento, é evidente que, para compreender-se o Direito Público francês atual, é preciso conhecer a sua história, suas fontes, suas principais instituições, as vicissitudes da sociedade francesa e o fluxo político.

Basta lembrar, por exemplo, da importância da lei vis-à-vis à Constituição e da proteção de direitos e liberdades; ou das singularidades de seu sistema semipresidencialista e da organização descentralizada da República - com suas diversas coletividades territoriais, cada qual com seu próprio estatuto jurídico. Da mesma forma, a democracia local direta, a separação de Poderes e a repartição de competências entre duas ordens de jurisdição (a judiciária e a administrativa), o Conselho de Estado e a Corte de Contas comprovam a especificidade das relações políticas, administrativas e financeiras entre o Estado francês e seus cidadãos, em comparação com o Direito brasileiro.

Além disso, como vimos, a articulação entre as fontes nacionais e as fontes europeias vem desafiando seus princípios e suas principais instituições, o que permite a nossos alunos a compreensão de problemas assentados em contexto real, favorecendo a transferência de conhecimentos.

\section{Conclusões}

A frutuosa parceria da FD com a UL - e, especialmente, com a Universidade Lyon 3 - não é isenta de aperfeiçoamentos. Analisada em perspectiva, observamos que o empreendimento resultou, fundamentalmente, do envolvimento pessoal dos parceiros da Universidade de Lyon 3, em especial da professora Caroline Chamard-Heim e dos reitores professores Hugues Fulchiron e Jacques Comby, além da intensa dedicação de professores da FD.

A parceria, em sentido amplo, encontra-se lastreada por um genérico convênio de cooperação acadêmica entre a USP e as universidades parceiras. No caso do PITES, inclusive do master, há convênios específicos. No caso dos Seminários Doutorais, foi o credenciamento das atividades em disciplinas de pós-graduação que lhes conferiu a necessária institucionalidade. Essa é, sem dúvida, uma solução eficaz, já adotada em outras experiências, como a da Cátedra Unesco de Direito à Educação da FDUSP, cujas atividades são desenvolvidas ao abrigo da pós-graduação, também sob a forma de disciplinas e eventos. 
Todavia, a operação e a gestão desses acordos são extremamente dependentes da iniciativa e da atuação dos docentes envolvidos, contando com a extrema boa vontade (ainda assim, a título pessoal) de alguns servidores administrativos. Essas condições realçam o caráter precário e personalíssimo das iniciativas, dado que, havendo alterações nas posições acadêmicas dos envolvidos, pode haver descontinuidade das atividades, com perdas acadêmicas e institucionais.

Faz-se necessário, portanto, institucionalizar processos, garantir continuidade aos acordos e assegurar suporte aos docentes envolvidos. A FD, certamente, conta com gestores comprometidos, além de meios materiais e humanos para alcançar estágios mais avançados de internacionalização das atividades da pós-graduação.

Iniciativas de internacionalização, nos níveis da graduação e da pósgraduação, demandam apoio institucional (celebração de acordos acadêmicos, reconhecimento das atividades etc.), financeiro (recursos para passagens e diárias, bolsas etc.) e operacional (escritório dedicado às providências, preparação de relatórios etc.) e, também, pessoal habilitado, inclusive para se comunicar em outros idiomas. Não é trivial levar-se a efeito atividades desse tipo, acrescidas das esperadas dificuldades burocráticas e da delonga para o início de sua oferta efetiva; e, mesmo superados os problemas, nem sempre alcançam sucesso. Isso não significa, de modo algum, que não valham o esforço, ao contrário: os ganhos acadêmicos para alunos e docentes envolvidos superam, em muito, as dificuldades.

No caso das parcerias com a UL, de parte dos brasileiros, fica patente um renovado interesse pelo Direito Público francês, com aplicações práticas no Brasil; de parte dos franceses, há o interesse pelo Brasil. Essa conjunção de esforços resgata, outrossim, a tradição da cooperação franco-brasileira no campo das humanidades, presente na criação da Universidade de São Paulo.

Uma outra vertente de comentários construtivos acerca da experiência dos Seminários Doutorais diz respeito à preparação dos alunos para as atividades no exterior. Aprendemos, ao longo desse período, que é preciso limitar o número de participantes, mediante uma seleção. A exigência de carta de motivação, explicitando as razões da escolha das disciplinas, e da compreensão do idioma francês são garantias de comprometimento e acompanhamento das atividades em Lyon.

Também é preciso informar os alunos acerca da "etiqueta universitária francesa", face às diferenças de costumes de ambas as sociedades, particularmente no que diz respeito à pontualidade. Por fim, as avaliações das atividades, propostas a alunos e professores envolvidos, têm colaborado para o seu aprimoramento.

Para concluir, parece-nos fundamental, no desenvolvimento de projetos inspirados na parceria com a UL e nas atividades das disciplinas de "Temas fundamentais de Direito Público francês", ter em mente que a pós-graduação stricto sensu visa à 
formação de pesquisadores, com efeitos significativos na capacitação de bons professores universitários. Numa universidade pública de pesquisa como a USP, refletir sobre o que ensinar, o que pesquisar e definir o perfil do profissional que se quer formar são pressupostos incontornáveis na consolidação da almejada internacionalização da FD. 